\title{
Modern Technologies for Producing Foamed Phosphate Glass for Oil Sorbents
}

\author{
K.G. Karapetyan ${ }^{1, a^{*}}$ and D.O. Sobyanina ${ }^{1}$ \\ ${ }^{1}$ Saint-Petersburg Mining University, St. Petersburg, Russia \\ a karapetyan_kgv@pers.spmi.ru
}

Keywords: Composite Materials, Foamed Glassy Phosphate Materials, Biosorbents, Surface Modification, Method of Molecular Layering, Purification of Water and Soil from Hydrocarbons

\begin{abstract}
The paper considers applications of foamed glassy phosphate materials as carriers of biologically active substances. The atomic layer deposition method allowed chemically synthesizing surface-modified composite materials based on graphite and carbon fibers, which maximally preserved the activity of enzymes and biologically active substances. The synthesis process of a mono-layer titanium-containing coating on the surface of graphite and carbon fibers by processing them with $\mathrm{TiCl}_{4}$ vapors is considered. The main characteristics of the graphite surface before and after modification and characteristics of the porous structure and surface of carbon fibers are obtained. Biologically active substances by adsorption from a solution to the surface of both the original and modified carriers were applied. biological activity and temperature stability of the obtained composite materials were studied. It is shown that the activity of a biologically active substance depends on the chemical composition and state of the surface of carbon-based carriers.
\end{abstract}

\section{Introduction}

Environmental problems have now acquired a global character and are expressed in irreversible changes in the conditions of human existence. In this regard, there are tasks of eliminating oil spills, products of condensation of exhaust gas aerosols in megacities, cleaning and restoration of technogenically destroyed territories, which include auto enterprises, technology parks, garages and parking lots, territories adjacent to highways and tunnels.

The solution of the above problems is possible by using the technology of complex biological cleaning of territories from oil pollution [1].

Currently used technologies for cleaning territories and eliminating oil spills have a number of disadvantages: firstly, the toxic effect of sorbents on the soil, and therefore the need to collect the sorbent from the surface to be cleaned and its disposal, and secondly, the mandatory implementation of a number of measures for additional soil restoration [2].

Taking into account these shortcomings and on the basis of previously performed studies [3], the biosorbent "BIAVA" was developed and patented, which is a porous sorbent carrier on the surface of which there are microorganisms-destructors of hydrocarbons and catalysts of biooxidation processes [4].

\section{Methods}

A foamed glassy phosphate material (foam glass) (Fig.1, a) with micro-additives of boron, cobalt, iron, copper, manganese, and molybdenum, which provide optimal conditions for the vital activity of microorganisms for a long time, was chosen as the carrier sorbent. The internal porous structure of the sorbent is shown in the photo (Fig.1, b) obtained using an electron microscope.Glasses for 
biosorbents were synthesized in the system at $1200-1300^{\circ} \mathrm{C}$ in the system (K2O-CaO-MdO-P2O5) from the charge in quartz crucibles for one hour with stirring. Good results of cooking in gasheated pot furnaces were achieved by using a liquid charge obtained from orthophosphoric acid.

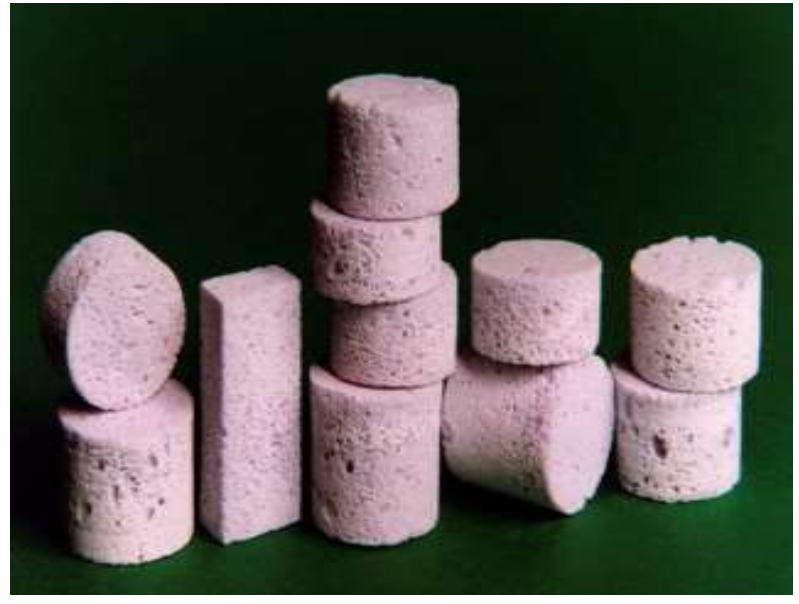

a

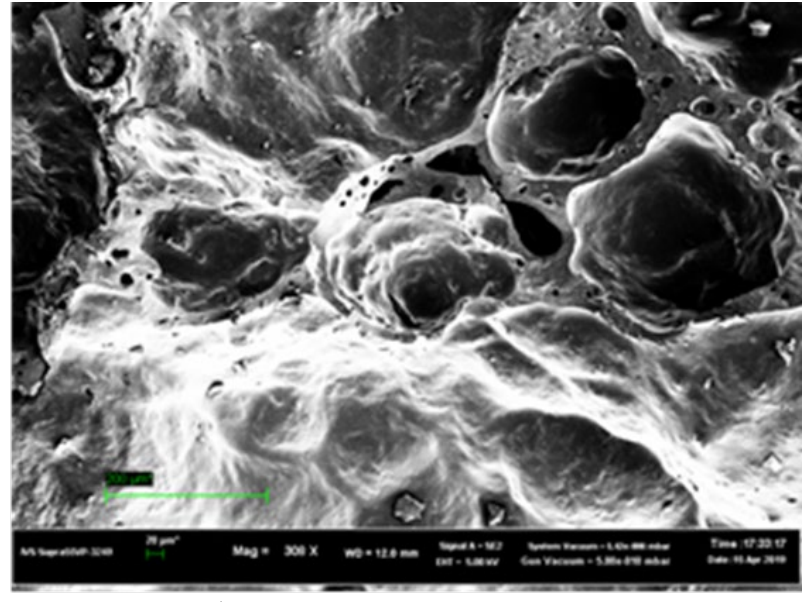

$\mathrm{b}$

Fig. 1. foamed glassy phosphate material (a), internal porous structure of the sorbent (b)

Also, the main raw materials used were magnesite concentrate, potassium carbon dioxide with a $\mathrm{K} 2 \mathrm{CO} 3$ content of at least $98 \mathrm{wt} . \%$, and apatite concentrate. The charge was loaded at a temperature of $1100-1150^{\circ} \mathrm{C}$ in portions. Each new portion was loaded onto the charge that had been boiled and was already in the crucible. Heating was carried out at a temperature of (1200$1250{ }^{\circ} \mathrm{C}$ ). The production of glass was carried out on metal plates and it's cooled in the air.

For the foaming of glass, a laboratory device was made, including a horizontally arranged tubular furnace, the temperature along the axis of which varies in the range of $150-700-150^{\circ} \mathrm{C}$. The foaming of the pellets inside the furnace was carried out in a "fluidized bed" with the tilt of the furnace, ensuring the continuous movement of the pellets at the desired speed. To maintain the pellets in a suspended state, a pipe was introduced into the working area of the furnace, through which air was blown from the compressor. During the research, the foaming temperature in the furnace varied within $520-620^{\circ} \mathrm{C}$ with an interval of $20{ }^{\circ} \mathrm{C}$.

When obtaining foamed samples based on phosphate glasses under laboratory conditions, the initial mixture was a mixture containing $66.7 \mathrm{wt} . \%$ of the phosphate glass powder fraction $\leq 1.25$ microns and $33.3 \%$ of the foaming agent. The mixture obtained in this way was moistened, and granules of 5-8 $\mathrm{mm}$ in size were pressed from it. Foaming was carried out in a gradient furnace, which was heated to $650^{\circ} \mathrm{C}$ (at the inlet-220 ${ }^{\circ} \mathrm{C}$, at the outlet-200 ${ }^{\circ} \mathrm{C}$ ) (Fig. 2) .

The production of foam glass granules includes the following stages:

- preparation of the initial mixture for foaming;

- forming of pellets;

- foaming of pellets.

The initial components of the mixture (glass powder and foaming agent) were ground in a ball mill to obtain a specific surface area of $1000-4000 \mathrm{~cm} 2 / \mathrm{g}$. The specific surface area was calculated based on the determination of the air permeability of the porous material. The analytical composition of the glasses was determined by the atomic emission method with inductively coupled plasma. It is shown that the difference in the compositions of glasses synthesized in both laboratory and industrial conditions does not exceed $1.0-1.5 \%$. 


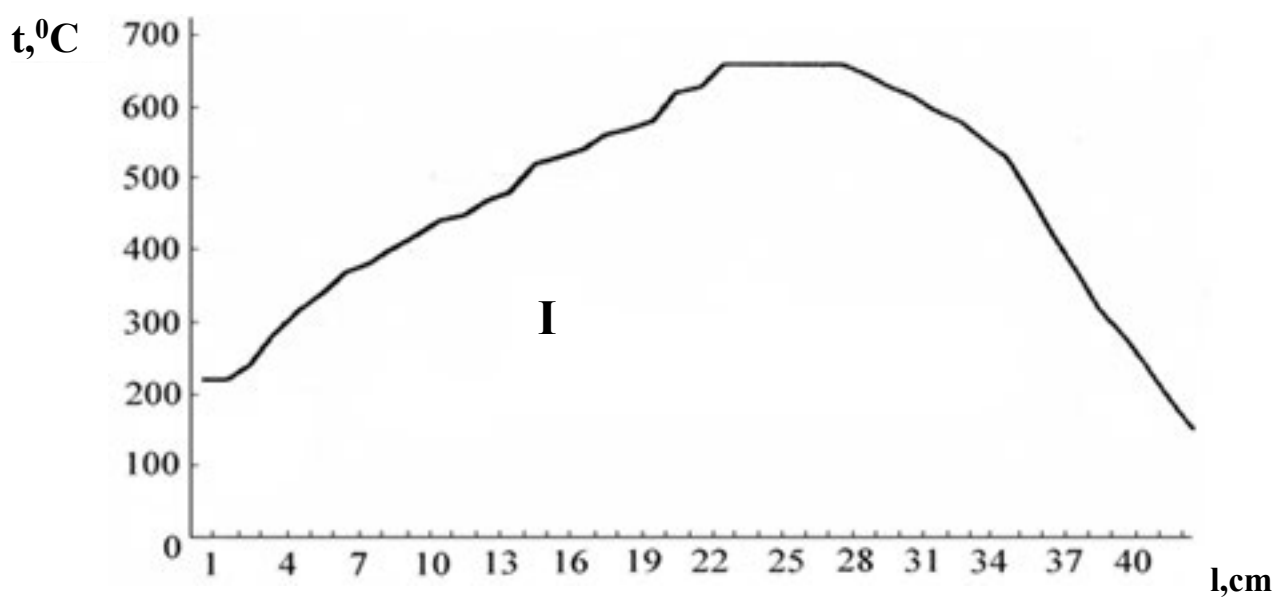

Fig. 2. Calibration curve: 1 - drying zone; 2 - hot zone; 3 - annealing zone

In order to change the chemical nature of the graphite surface, we synthesized monolayer coatings based on elemental layers of titanium and zirconium. One of the effective methods for their synthesis is the atomic layer deposition (ALD) method [5 - 10]. The main advantages of the ALD technology are: control the thickness of the resulting film (a coating of several nanometers), reagents don't interact with each other until they reach the substrate, obtaining a uniform film thickness on the substrate.

The route allows forming covalently-bound monolayer coatings on the substrate surface. Importantly, the synthesis process allows depositing a self-assembled element oxychloride monolayer, since the treatment time required to achieve a maximum coverage is determined by exhaustion of the active surface sites. As a result, a highly reproducible and conformal coating can be obtained [11].

The proteolytic enzyme trypsin was chosen as a model system of biologically active substances. Trypsin is an enzyme preparation with a proteolytic effect, has pronounced anti-inflammatory and decongestant properties, is able to break down dead tissue, fibrinous formations, viscous secrets and exudates. In relation to healthy tissues, the enzyme is inactive and safe. This drug can be used as a part of coatings of artificial organs, vessels during implantations. Immobilization of trypsin on a carrier will allow maintaining the enzyme activity at a sufficiently high level, prologging its action and increasing resistance to destabilizing factors.

Trypsin immobilization on the surface of carbon materials was carried out by adsorption. The catalytic activity of trypsin was determined spectrophotometrically from the decomposition products of casein.

\section{Results and discussion}

Evidently (Table 1), the concentration of oxygen-containing functional groups increases significantly after oxidation and slightly decreases as a result of successive cycles of formation of titanium oxide layers.

The studied carbon fibers are characterized by a small volume of macropores and a specific surface area of not more than $50 \mathrm{~m}^{2} / \mathrm{g}$ (table 2). These results indicate a low sorption activity of the studied carbon fibers.

The changes in the surface characteristics of the initial and modified graphite correspond to the dependence of the immobilized trypsin amount on the number and chemical composition of the 
titanium and zirconium oxide layers (Fig. 3, curves $1^{\prime}$ and $2^{\prime}$ ). With an increase in the number of cycles of graphite surface treatment by the ALD method, the number of active functional groups of the surface decreases, which leads to a decrease in the amount of adsorbed enzyme.

Table 1. Characteristics of the surface of original and modified graphite

\begin{tabular}{|l|c|c|}
\hline \multicolumn{1}{|c|}{ Sample } & $\begin{array}{c}\text { Static exchange capacity } \\
\text { for } \mathrm{NaOH}\left[\mu \mathrm{mol} / \mathrm{m}^{2}\right]\end{array}$ & $\begin{array}{c}\text { Specific surface } \\
{\left[\mathrm{m}^{2} / \mathrm{g}\right]}\end{array}$ \\
\hline Original graphite & 70 & 16.0 \\
\hline Oxidized graphite & 3.00 & 17.0 \\
\hline $\begin{array}{l}\text { Graphite modified with titanium oxide } \\
\text { groups (after 1. Treatment cycle) }\end{array}$ & 2.85 & 15.5 \\
\hline $\begin{array}{l}\text { Graphite modified with titanium oxide } \\
\text { groups (after 2. Treatment cycle) }\end{array}$ & 2.80 & 15.3 \\
\hline $\begin{array}{l}\text { Graphite modified with titanium oxide } \\
\text { groups (after 3. Treatment cycle) }\end{array}$ & 2.65 & 14.9 \\
\hline $\begin{array}{l}\text { Graphite modified with titanium oxide } \\
\text { groups (after 4. Treatment cycle) }\end{array}$ & 2.50 & \\
\hline
\end{tabular}

Table 2. Characteristics of the porous structure and surface of carbon fibers

\begin{tabular}{|c|c|c|c|c|}
\hline $\begin{array}{c}\text { Sample of } \\
\text { carbon fibers }\end{array}$ & $\begin{array}{c}\text { Heat treatment } \\
\text { temperature }[\mathrm{K}]\end{array}$ & $\begin{array}{c}\text { pore volume, } \\
\mathrm{m}^{3} / \mathrm{g}\end{array}$ & $\begin{array}{c}\text { Static exchange capacity for } \\
\mathrm{NaOH}\left[\mu \mathrm{mol} / \mathrm{m}^{2}\right]\end{array}$ & $\begin{array}{c}\text { Specific surface } \\
{\left[\mathrm{m}^{2} / \mathrm{g}\right]}\end{array}$ \\
\hline gralen & 2073 & 02 & 05 & 15 \\
\hline uglen & 1173 & 16 & 12 & 50 \\
\hline licron & 773 & 03 & 03 & 18 \\
\hline
\end{tabular}

At the same time, samples modified with titanium and zirconium oxide layers show an increase in the activity of the immobilized enzyme (Fig. 3, curves 1 and 2). Obviously, samples based on graphite modified after 4 cycles of sequential deposition of zirconium oxide layers with an enzyme activity of about $80 \%$ were obtained (Fig. 3, curve 1).

As a result of surface modification of carbon fiber uglen by zirconium containing coatings, composite materials with the following surface characteristics were obtained (Table 3 ).

Table 3 shows that it was impossible to significantly increase the biological activity of carbon fiber-based composite materials. Apparently, the interaction of the enzyme molecule with the surface of the carbon fiber changes the tertiary structure of the molecules, which leads to a decrease in catalytic activity. The main reason for the decrease in catalytic activity is usually the formation of associates of enzyme molecules on the surface and blocking of the active center of the enzyme. 
Table 3. Characteristics of the surface of original and modified carbon fibers uglen

\begin{tabular}{|l|c|c|c|}
\hline \multicolumn{1}{|c|}{ Sample of carbon fibers } & $\begin{array}{c}\text { Zirconium content in } \\
\text { the sample }\left[\mu \mathrm{mol} / \mathrm{m}^{2}\right]\end{array}$ & $\begin{array}{c}\text { Specific } \\
\text { surface }\left[\mathrm{m}^{2} / \mathrm{g}\right]\end{array}$ & $\begin{array}{c}\text { Biological } \\
\text { activity A [\%] }\end{array}$ \\
\hline original uglen & 0 & 50 & 32 \\
\hline $\begin{array}{l}\text { uglen modified with zirconium oxide } \\
\text { groups (after 1st treatment cycle) }\end{array}$ & 4 & 47 & 39 \\
\hline $\begin{array}{l}\text { uglen modified with zirconium oxide } \\
\text { groups (after 2nd treatment cycle) }\end{array}$ & 9 & 38 & 45 \\
\hline $\begin{array}{l}\text { uglen modified with zirconium oxide } \\
\text { groups (after 3ed treatment cycle) }\end{array}$ & 1.3 & 30 & 47 \\
\hline $\begin{array}{l}\text { uglen modified with zirconium oxide } \\
\text { groups (after 4th treatment cycle) }\end{array}$ & 1.7 & 25 & 49 \\
\hline
\end{tabular}

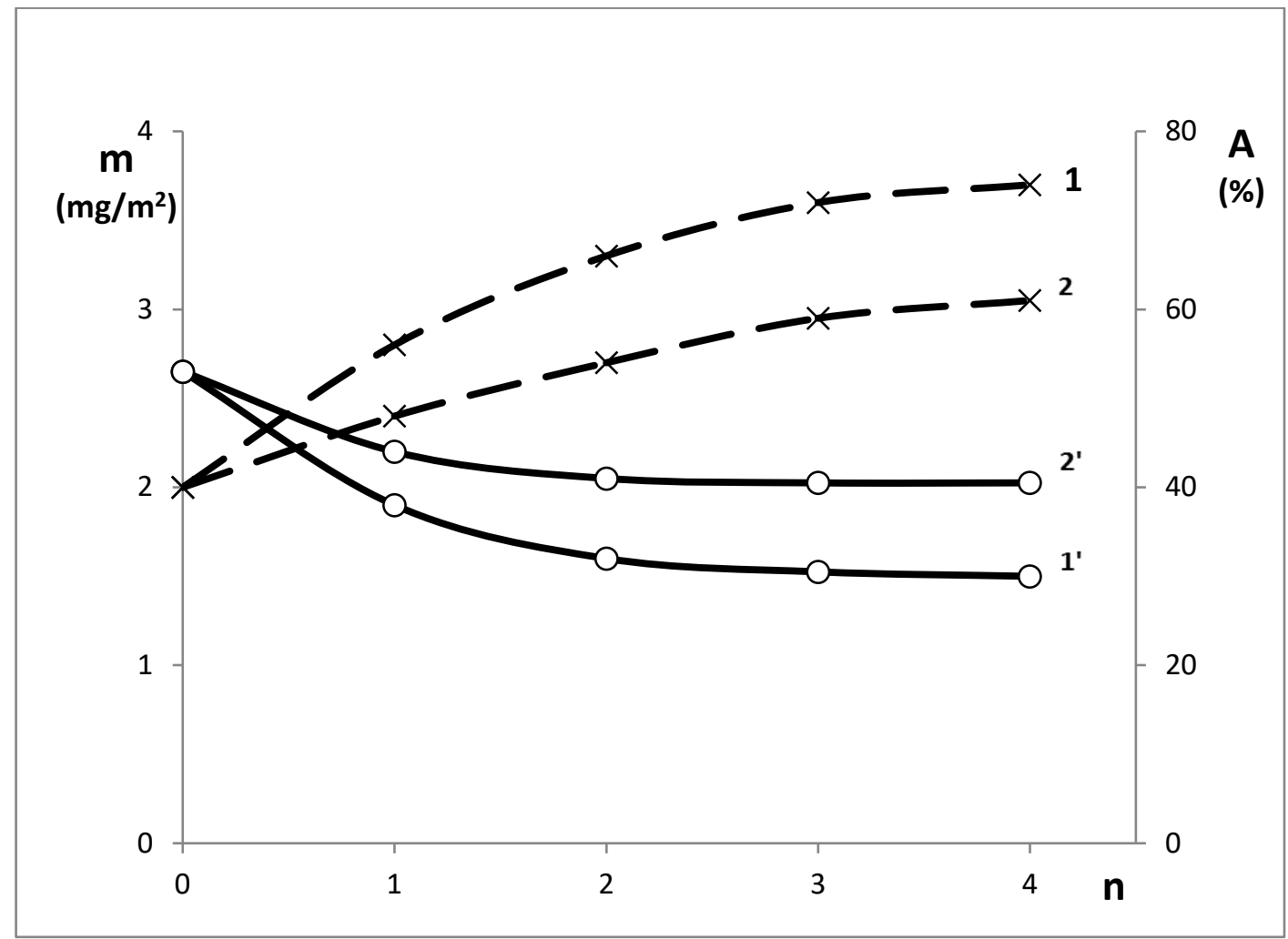

Fig. 3. Dependences of the amount of immobilized trypsin $\boldsymbol{m}(1,2)$ and biological activity $\boldsymbol{A}$ $(1,2)$ on the number and chemical composition of element-oxide layers $\boldsymbol{n}$

\section{Summary}

Thus, the decrease in trypsin activity during adsorption on carbon carriers can be due to two factors: the influence of the chemical nature of the active surface centers, as well as the formation of inactive surface associates of the enzyme at high degrees of filling of the carrier surface.

When trypsin was immobilized on a graphite surface with a zirconium-containing coating, samples were obtained with biological activity of about $80 \%$ of the activity of the free enzyme in solution, possessing resistance of the biologically active substance to elevated temperature and $\mathrm{pH}$, the capability of repeated use, which enables further use of these composite materials for the production of electrochemical biosensors. 
Thus, changing the chemical nature of the graphite surface by modifying the surface with monolayer titanium and zirconium-containing coatings allows for directional control of the adsorption activity of the surface and production of materials with predictable properties and high catalytic activity for biomedical sensors and other industrial purposes.

\section{References}

[1] V.E. Kogan, K.G. Karapetyan, Phosphate glasses as a basis of ecologically safe fertilizers of prolonged action and biosorbents-hydrocarbon destructors, Int. multidisciplinary scientific geoconference surveying geology and mining ecology management, SGEM, 18(5.1) (2018) 637644. https://doi.org/10.5593/sgem2018/5.1/S20.082

[2] P'Yanova, L.G.,, Sedanova, A.V.,. Drozdetskaya, M.S. Synthesis and Research of Modified Carbon Sorbents with Hydroxy Acids (2016) International Conference on Oil and Gas Engineering, OGE 2016; Omsk State Technical UniversityOmsk; Russian Federation vol 152 pp. 639-646. https://doi.org/10.1016/j.proeng.2016.07.668

[3] P'Yanova, Kornienko, N.V., Suprunyuk, V.A., Study of the adsorption properties of molded carbon sorbents in relation to organic dyes in model conditions. AIP Conference Proceedings (2019) Volume 2143 N 020006. https://doi.org/10.1063/1.5122905

[4] I.V Pleskunov, A.G. Syrkov, Development of research of low-dimension metal-containing systems from P.P. Weymarn to our days, J. of mining instit. 231 (2018) 287-291.

[5] Basso A. Industrial applications of immobilized enzymes: A review/ Basso A., Serban, S.// Molecular Catalysis -2019 - V.479-110607. https://doi.org/10.1016/j.mcat.2019.110607

[6] T. Kääriäinen, A. Cameron, M.-L. Aäriäinen, K.A. Sherman, Atomic Layer Deposition: Princples, Characteristics, and Nanotechnology Applications, Book, John Wiley and Sons, 2013. https://doi.org/10.1002/9781118747407

[7] V. Miikkulainen, M. Leskelä, M. Ritala, R. Puurunen, Crystallinity Of Inorganic Films Grown By Atomic Layer Deposition: Overview And General Trends, J. Of Applied Physics 113(2) (2013) 021301. https://doi.org/10.1063/1.4757907

[8] Johnson, R.W., Hultqvist, A., Bent, S.F. A brief review of atomic layer deposition: From fundamentals to applications. (2014) Materials Today, 17 (5), pp. 236-246.

https://doi.org/10.1016/j.mattod.2014.04.026

[9] Yatsenko, E.A., Gol’tsman, B.M., Kosarev, A.S., Karandashova, N.S., Smolii, V.A., Yatsenko, L.A. Synthesis of Foamed Glass Based on Slag and a Glycerol Pore-Forming Mixture // Glass Physics and Chemistry, 2018, Vol. 44(2), P. 152-155.

https://doi.org/10.1134/S1087659618020177

[10] Yatsenko, E.A., Zubekhin, A.P., Smolii, V.A., Grushko, A.S., Gol'tsman, B.M. ResourceConserving Technology of Heat-Insulation-Decorative Glass-Composite Material Based on AshSlag Wastes // Glass and Ceramics, 2015, Vol. 72(5-6), P. 216-219. https://doi.org/10.1007/s10717-015-9759-6

[11] Denisova, O.V., Rastvorova I.I. (2020) Carbon materials for immobilization of biologically active substances. Key Engineering Materials, 2020, 836 KEM, 52-57.

https://doi.org/10.4028/www.scientific.net/KEM.836.52 